\title{
MACROSOMIC BIRTHS IN A TERTIARY PUBLIC HOSPITAL: A SURVEY OF MATERNAL CHARACTERISTICS AND FETAL OUTCOME
}

\author{
James Osaikhuwuomwan $^{1}$, abieyuwa Osemwenkha ${ }^{1}$, godwin Orukpe ${ }^{1}$
}

ABSTRACT

BACKGROUND: Macrosomic fetuses are high risk with their delivery process being associated with potential risk to both mother and baby The aim of this study is to determine the incidence of macrosomic births and the associated maternal characteristics and to ascertain the fetal outcome.

METHODS: It was a retrospective survey of maternal characteristics and pregnancy outcome of macrosomic births. Comparison was made with the next selected normal birth weight delivery during the study period.

RESULTS: There were 8607 deliveries during the period (3 years) reviewed. Of this, 306 were macrosomic deliveries, a frequency of 3.6\%. The mean weight for macrosomic babies was $4.23 \mathrm{~kg}$ (range $4.01-5.62 \mathrm{~kg}$ ). There was a higher mean maternal weight and gestational age of mothers with macrosomic deliveries compared to mothers in the control group, $(85.87 \pm 19.39 \mathrm{~kg}$ vs $74.92 \pm 19.11 \mathrm{~kg}$ $P<0.01$; and $41.51 \pm 1.46$ vs $39.02 \pm 1.29, P<0.001)$. Caesarean delivery was significantly associated with macrosomic births compared to controls, $p<0.0001$, odds ratio 3.977. Also, asphyxia and shoulder dystocia occurred more in macrosomic babies, $10.4 \%$ vs $2.9 \%$ and $2.28 \%$ vs $0.65 \%, P<0.001$. The majority of the asphyxiated babies amongst macroomic births were following vagina delivery compared to caesarean delivery, (65.6\% vs 34.4\%) $p=0.001$. There were 3 cases of still birth in the macrosomic deliveries, but no maternal deaths were encountered.

CONCLUSION: Macrosomic births could be tragic. Although delivery outcome seems better with a caesarean section, good fetal outcome can only be assured on the premise of astute labour and delivery management.

KEYWORDS: fetal macrosomia, pregnancy, labour, delivery, fetal outcome

DOI: http://dx.doi.org/10.4314/ejhs.v26i1.7

\section{INTRODUCTION}

A big baby or fetal Macrosomia poses great risk during pregnancy, labour and delivery. It is associated with increased maternal and perinatal morbidities but rarely mortalities (1-3). Moreso, larger babies carry a greater risk of developing type 2 Diabetes Mellitus, increased risk of premenopausal breast cancer and an increased risk of becoming overweighed later in life $(4,5)$. The risk to mother and newborn increases significantly as fetal weight increases beyond $4.0 \mathrm{~kg}$ (6). The most encompassing definition of fetal macrosomia is a birth weight above $90^{\text {th }}$ percentile irrespective of gestational age and size $(1,2)$. However, most obstetricians agree that birth weight 4000-4500 gramms and above is macrosomic $(1,2)$. Due to variation of the minimum weight that defines macrosomia, the incidence also varies depending on the cutoff value but ranges between $1-10 \%$ of all deliveries (7). In the United States of America, fetal macrosomia account for over $10 \%$ of all their deliveries and $4.5 \%$ in Saudi Arabia (8). The incidence of fetal macrosomia is $2.5 \%$ in Abia, South Eastern Nigeria (9), 3\% in Jos, Northern Nigeria (10), $8.1 \%$ in a study done by Ezeagwu et al (11) at the UNTH Enugu in Nigeria and $8.1 \%$ in

\footnotetext{
${ }^{1}$ Department of Obstetrics and Gynaecology, College of Medical Sciences, University of Benin, Nigeria Corresponding Author: Osaikhuwuomwan J., Email: jagbons1@yahoo.com
} 
Benin (12). Genetic, racial and ethnic factors have been shown to influence birth weight and fetal macrosomia (13).

Other factors associated with fetal macrosomia include maternal diabetes, multiparity, previous history of macrosomic deliveries, increased body mass index or obesity, excessive weight gain in pregnancy and parental height $(6,14)$. Recent studies have also suggested that pre-pregnancy body mass index (BMI) or maternal weight is the most important predictor of delivery of macrosomic baby in non diabetic mothers $(6,9)$.

Macrosomic delivery has been predicted by history (maternal characteristics) and fetal outcome of previous deliveries in parous women. This has also been done with clinical estimation and/or sonographic biometric measurement of fetal parts in conjuction with regression equation (15). The American College of Obstetrics and gynaecology in its guideline on fetal macrosomia declared that diagnosis of fetal macrosomia is imprecise (16). Thus, fetal outcome of macrosomic delivery is largely determined by the events at delivery.

The most feared complication of macrosomia is shoulder dystocia and $25 \%$ of infants with shoulder dystocia experience brachial plexus, facial nerve injury, fracture of the humerous or clavicle beside traumatic maternal genital tract injuries (17). Incidence of still birth has also been reported in addition to various degrees of asphyxia following macrosomic deliveries either by abdominal or vagina route $(8,12,18)$.

The macrosomic fetus presents a huge clinical challenge to the obstetrician. Thus, this study was set out to survey macrosomic delivery in a public tertiary referral with a view to documenting the prevalence of macrosomic deliveries as well as the predisposing maternal characteristics and the fetal outcome of these deliveries. The findings may aid in improving clinical practice and pregnancy outcome.

\section{MATERIALS AND METHOD}

The study was conducted at the University of Benin Teaching Hospital in Benin City, a public tertiary referral centre in Southern Nigeria. It was a 3 year retrospective review of macrosomic deliveries between January $1^{\text {st }} 2011$ and December $31^{\text {st }}, 2013$, analysing associated maternal characteristics and pregnancy outcome and comparing these to selected normal birth weight deliveries.

Data on all the singleton term deliveries were extracted to include maternal age, gestational age at delivery, maternal weight, height, parity, previous history of macrosomic deliveries and medical condition as diabetes in pregnancy. Gestational age at delivery was recorded as determined by last menstrual period or ultrasound scan done not more than the $20^{\text {th }}$ week of pregnancy. Mode of delivery, outcome of the delivery such as weight, APGAR score in the first minute and any events of shoulder dystocia, still birth or admission to the special care baby unit were also extracted.

Records were extracted from the case notes, labour ward theatre and other delivery record books in the hospital. All babies with birth weight $4.0 \mathrm{~kg}$ and above were considered as macrosomia and selected as the study group while every next uncomplicated record of normal delivery (weight less than $4.0 \mathrm{~kg}$ ) served as control. Only singleton term deliveries were included in this study. Preterm deliveries, cases of intrauterine fetal death and multiple pregnancies were excluded. Comparative analysis was done between the two groups. The study protocol was approved by the ethical committee of the hospital. Data were analyzed using SPSS version 16 software (SPSS Inc.,Chicago, IL) and INSTAT stastical package as appropriate; all tests were two-tailed, and $\mathrm{p}<0.05$ was considered statistically significant. Continuous variables were presented as mean(SD) and tested by the independent samples Student's T-test while categorical data were expressed as numbers and test for association done using the Chi-square test.

\section{RESULTS}

There were 8607 deliveries during the period reviewed, and 306 of these were macrosomic births accounting for $3.6 \%$ of total deliveries. The mean weight of the macrosomic births and normal birth weight was $4.23 \mathrm{~kg}$ and $3.24 \mathrm{~kg}$ respectively; a range of between $4.01-5.62 \mathrm{~kg}$ for the macrosomic babies and $2.50-3.91 \mathrm{~kg}$ for normal birth weight babies. Table 1 shows the age distribution of the mothers with macrosomic delivery in the study period; women aged $21-30$ years delivered more macrosomic babies, 
174(49.7\%). In Table 2, maternal characteristics between the two groups are compared. The mean age of mothers with macrosomic deliveries was $29.61 \pm 6.85$ years, and that of the nonmacrosomic delivery was $29.70 \pm 6.78$ years, $\mathrm{P}>0.05$. When the mean parity of the mothers with macrosomic babies and the control group was compared, there was no significant association between parity and macrosomic birth; $1.45 \pm 1.27$ and $1.29 \pm 1.28$ respectively, $\mathrm{P}$-value $>0.05$. While the mean maternal weight of mothers with macrosomic deliveries was significantly higher compared to weight of mothers in the control group, $(85.87 \pm 19.39 \mathrm{~kg}$ vs $74.92 \pm 19.11 \mathrm{~kg}$
$(\mathrm{P}<0.01)$; there was no statistically significant difference in mean maternal height in the two groups, $163.4 \pm 10.02 \mathrm{~cm}$ and $163.7 \pm 5.28 \mathrm{~cm}(\mathrm{P}-$ value $>0.05$ ). The mean gestational age of mothers with fetal macrosomia was $41.51 \pm 1.46$ and significantly higher than that of mothers with normal birth weight, $39.02 \pm 1.29$ (P-value $<0.001)$. A history of previous macrosomic births was positively associated with macrosomic deliveries in the index study period $22 \%$ vs $3.6 \%$ (controls), $\mathrm{p}<0.05$. Similarly, the majority of mothers with diabetes mellitus in pregnancy had macrosomic babies compared to normal birth weight; $12.7 \%$ vs $3.9 \%, \mathrm{P}=0.001$.

Table 1: Age Distribution of Mothers

\begin{tabular}{llll}
\hline Age & $\begin{array}{l}\text { No of Macrosomic } \\
\boldsymbol{f},(\boldsymbol{\%})\end{array}$ & $\begin{array}{l}\text { Non-Macrosomic } \\
\boldsymbol{f},(\boldsymbol{\%})\end{array}$ & Total \\
\hline$<20$ & $24(52.2)$ & $22(47.8)$ & 46 \\
$21-30$ & $174(49.7)$ & $176(50.3)$ & 350 \\
$31-40$ & $72(49.7)$ & $73(50.3)$ & 145 \\
$41-50$ & $36(50.7)$ & $35(49.3)$ & 71 \\
Total & 306 & 306 & 612 \\
\hline
\end{tabular}

Table 2: Maternal Characteristics

\begin{tabular}{llll}
\hline Maternal Characteristics & Macrosomic(306) & Non-Macrosomic(306) & P-value \\
\hline Mean age (years) & $29.61 \pm 6.85$ & $29.70 \pm 6.78$ & $\mathrm{P}>0.05$ \\
Mean parity & $1.45 \pm 1.27$ & $1.29 \pm 1.28$ & $\mathrm{P}>0.05$ \\
Mean material weight & $85.87 \pm 19.39$ & $74.92 \pm 19.11$ & $\mathrm{P}<0.001$ \\
Maternal height & $163.4 \pm 10.02$ & $163.7 \pm 5.28$ & $\mathrm{P}>0.05$ \\
Mean Gestational age & $41.51 \pm 1.46$ & $39.02 \pm 1.29$ & $\mathrm{P}<0.001$ \\
Previous history & $69(22.5 \%)$ & $11(3.6 \%)$ & $\mathrm{P}<0.001$ \\
Diabetes in pregnancy & $39(12.7 \%)$ & $12(3.9 \%)$ & $\mathrm{P}<0.001$ \\
\hline
\end{tabular}

Table 3 shows the route of deliveries in the study period. Caesarean section rate was higher in the women with macrosomic babies representing $41.2 \%$ compared to $15.7 \%$ in the mothers with non-macrosomic babies, and this was statistically significant $(\mathrm{P}<0.001)$. There were also more instrumental deliveries amongst the macrosomic group $4.9 \%$ against $2.6 \%$ in the control group. Notably, most cases of caesarean section among the macrosomic deliveries were due to cephalopelvic disproportion secondary to fetal macrosomia. 
Table 3: Mode of Delivery

\begin{tabular}{lllll}
\hline Baby size & $\begin{array}{l}\text { Caesarean } \\
\boldsymbol{f}(\boldsymbol{\%})\end{array}$ & $\begin{array}{l}\text { Section(c/s) Instrumental } \\
\text { Deliveries, } \boldsymbol{f}(\boldsymbol{\%})\end{array}$ & $\begin{array}{l}\text { Vaginal Delivery (svd) } \\
\boldsymbol{f ( \boldsymbol { \% } )}\end{array}$ & Total \\
\hline Macrosomic & $126(41.2)^{\times} \alpha$ & $15(4.9)$ & $165(53.9) \alpha$ & 306 \\
Non-Macrosomic & $48(15.7)^{\times}$ & $8(2.6)$ & $250(81.7)$ & 306 \\
& $\mathbf{1 7 4}(\mathbf{2 8 . 4})$ & $\mathbf{2 3}(\mathbf{3 . 8})$ & $\mathbf{4 1 5}(\mathbf{6 7 . 8})$ & $\mathbf{6 1 2}$ \\
\hline $\mathrm{x}=p<0.05, \quad \alpha=\mathrm{c} / \mathrm{s}$ vs svd: $\mathrm{p}=0.0001$, OR 3.977, 95\%CI 2.703-5.853 & &
\end{tabular}

Fetal outcome is compared in Table 4; Asphyxia in this study was defined as APGAR score in the first minute of life of less than 7. There were $32(10.4 \%)$ cases of birth asphyxia in the macrosomic group and $9(2.94 \%)$ in the normal weight babies. There were 4 cases of still birth among the macrosomic babies-2 were due to complication of maneuvers for delivery of shoulder dystocia. One of the macrosomic deaths was unexplained fresh still birth in a diabetic mother. The case of still birth in the normal weight range was that of cord accident discovered at delivery. There were 7 cases of shoulder dystocia representing $2.28 \%$ of the macrosomic group and $2(0.65 \%)$ cases in the normal birth weight group. Of the 32 asphyxiated babies in the study group, $21(65.6 \%)$ occurred at vagina delivery while $11(34.4 \%)$ at caesarean delivery, $\mathrm{p}=0.001$. Although $3(75 \%)$ of the 4 cases of still birth amongst the study group occurred following vaginal delivery compared to $1(25 \%)$ following abdominal delivery, the difference was not significant, $\mathrm{p}>0.05$.

Table 4: Fetal Outcome

\begin{tabular}{llll}
\hline Fetal & $\begin{array}{l}\text { Macrosomic } \\
\text { Characteristics }\end{array}$ & $\begin{array}{l}\text { Non-Macrosomic } \\
\mathbf{f = 3 0 6 , ( \% )}\end{array}$ & P-value \\
\hline Asphyxia & $32(10.4)$ & $9(2.94)$ & $\mathrm{P}<0.001$ \\
Still Birth & $4(1.30)$ & $1(0.32)$ & $\mathrm{P}<0.001$ \\
Shoulder Dystocia & $7(2.28)$ & $2(0.65)$ & $\mathrm{P}<0.001$ \\
\hline
\end{tabular}

\section{DISCUSSION}

The rate of macrosomic births in this study of $3.6 \%$ is in consonance with the trend previously documented (7-12). In this survey, macrosomic delivery was positively associated with higher maternal weight, previous history of macrosomic delivery, maternal diabetes mellitus and increased gestational age at delivery. The aforementioned risk factors (maternal characteristics) are some of the major factors reported in theb literature $(6,11,13,19)$. A previous study in this province identified diabetes in pregnancy as a significant risk factor for fetal macrosomia (12). Mutihir and Co demonstrated an association between postmaturity and fetal macrosomia; mothers with higher gestational age delivered more macrosomic babies (10). Boyd et al reported that about $38 \%$ of pregnant women will have at least one risk factor while about $34 \%$ of macrosomic newborn are delivered without any maternal risk factors (6). In this study, there was at least one identifiable risk factor for each macrosomic delivery; however, some recognized factors, such as maternal age and parity $(6,14)$, were not significantly associated with macrosomic deliveries in this study. This may be due to the small size of the study population or the influence of genetic, racial or ethnic factors (13).

The importance of suspicion or diagnosis of fetal macrosomia stems from the need to anticipate and thus forestall complications that may arise. While shoulder dystocia remains one of the most feared complications associated with fetal macrosomia, stillbirths have also been reported (17). This was corroborated in this survey with the finding of a higher incidence of shoulder dystocia, still births and birth asphyxia amongst macrosomic deliveries. These adverse fetal outcomes suggest difficulties encountered at the delivery process owing probably to manipulations to attempt to fit or squeeze the big baby through 
the delivery outlet; it may also reflect innate potential metabolic problems in the macrosomic fetus (especially in the diabetic mother). Previous studies have reported an association between big babies and genetic syndromes/disorders $(7,8)$.

The majority of the feared complications are associated with vaginal delivery. In this study, vaginal delivery accounted for $53.9 \%$ of all the macrosomic deliveries, and there were more unfavourable outcomes for babies delivered via this route such as shoulder dystocia, birth asphyxia and even stillbirth. In analyzing the impact of mode of delivery on the outcome of macrosomic babies, we observed that there were four cases of stillbirths; of these, three were following vaginal delivery. Two of the three vaginal births were due to maneuvers to relief shoulder dystocia in macrosomic babies. Asphyxia at birth was also more common following vaginal delivery; this is slightly lower than incidence of fetal asphyxia reported in previous study done in Zaria (18). The foregoing discussion makes the decision on the mode of delivery (especially vaginal) of macrosomic babies daunting (16). Thus, caesarean section has become a major route of delivery of the macrosomic babies as observed in this study. The caesarean deliveries were largely due to cephalopelvic disproportion, and are similar to the findings of Abudu et al (20). Early decision on caesarean section and judicious monitoring of labour may explain the relative lower incidence of asphyxia in this study.

The observations of this study viz-a-viz associated maternal predictive characteristics for fetal macrosomia and the increased incidence for asphyxia and interventional delivery further corroborates with previous findings $(3,4,9,16)$. However, conclusions and deductions from this study cannot be assertive because of the limitations of its retrospective nature and the small sample size.

In conclusion, fetal macrosomia is associated with maternal diabetes, increased maternal weight and higher gestational age. The delivery outcome is better following abdominal delivery; however, while caesarean delivery (compared to vaginal route) may reduce the risk of birth trauma/asphyxia in macrosomic fetuses, it does not eliminate the risk. Thus, knowledgeable anticipation and astute supervision with timely decision on the labour and delivery process is key to a desirable outcome.

\section{REFERENCES}

1. Haram K, Pirhonem J, Bergsjo P. Suspected big baby. A difficult clinical problem in obstetrics. Act Obst Gynecol scand, 2002; 81: 185-94.

2. America College of obstetrics and gynecology. Fetal macrosomia. ACOG practice bulletin No. 22 Washington DC 2000.

3. Kolderup LB, Laros RK, Musa TJ. Incidence of persistent birth injuries in macrosomic infants. Association with mode of delivery. Am. Journal of Obst Gynaecol, 1997; 177: 3741.

4. Oral E, Cagdas A, Kaleli S, Aydinli K. Perinatal and maternal outcome of fetal macrosomia. Eur Journ Obst Gynaecol Reprod Biol, 2001; 99:167-171.

5. Aye SS, Saxena S. Management of large for gestational age pregnancy in non diabetic women. TOG 2010; 12: 250-256.

6. Boyd ME, Usher RH, Maclean. Fetal macrosomia, prediction, risk proposed management. Obst Gynaecol, 1983;61(5) 71522.

7. Henrisken T. The macrosomic fetus a challenge in current obstetrics. Acta Obst. Gynecol Scand, 2008; 87: 134-45.

8. Aisamani MA, Ahmed SR. Fetal and maternal outcome in pregnancies complicated with fetal macrosomia. North Am J Med Sci, 2012; 4: 283-6.

9. KC.amanu CI, Onwere S, Chigbu B, Aluka C, Okoro O, Obasi M. Fetal macrosomia in African women, a study of 249 cases. Achives of gynecol, 2009; 279 (6): 857-61.

10. Mutihir JT, Ujah A. Postmaturity and fetal macrosomia in Jos, Nigeria. Annals of African medicine, 2005:4(2):72-76.

11. Ezegwu HU, Ikeako LC, Egbuji. Fetal macrosomia. Obstetric outcome of 311 cases in UNTH Enugu, Nigeria. Niger J Clin Pract, 2011; 14: 322-6.

12. Onyiruka AN. High birth weight babies. Incidence and fetal outcome in a mission Hospital in Benin City. Nig J Clin Pract, 2008; 9: 116-9.

13. Okun N, Verma A, Mitchel BF, Flowerdew G. Relative importance of maternal constitutional 
factors and glucose intolerance of pregnancy in developing newborn macrosomia. Journal of maternofetal and neonatal medicine, 1997; 6 (5):285-290.

14. Stotland NE, Caughey AB, Breed EM, Escobar GJ: Risk factors and obstetric complications associated with macrosomia.Int J Gynaecol Obstet, 2004; 87(3):220-226.

15. Coombs CA, Rossen B, Miodovnik Sadiqui TA. Sonographic estimated fetal weight and fetal macrosomia. Journ of Maternofetal Medicine, 2000; 9: 55-61.

16. America College Of Obstetrics and gynecology. Guideline on fetal macrosomia. Am Fam Physician, 2001 Jul 1; 64(1): 167170.
17. Gherman RB, Ouzounian JG, Goodwin TM. Obstetrics maneuvers for shoulder dystocia and associated fetal morbidities. Am J Obstet Gynecol, 1998; 178: 112-1130.

18. Ahmed AA. Perinatal presentation and outcome of high birth weight in Zaria Nigeria. Nig Journ of Paed, 2011; 38 (2): 65-72.

19. Lim JH, Tan BC,Jammel AE, Symond EM. Deliveries of macrosomic babies, management and outcome of 330 cases. J Obstet Gynecol, 2002; 22: 370-4.

20. Abudu OO, Awonuga AO. Fetal macrosomia and pregnancy outcome in Lagos. Int. Journ of obst and gynecol, 1989; 28(3): 25-7. 